\title{
El barrio de Santiago en el centro histórico de Mérida. Del garbo al deterioro y a la ulterior revitalización
}

\section{The Santiago neighborhood in the historic center of Mérida. From elegance to deterioration and subsequent revitalization}

Claudia Dávila Valdés*

Ricardo López Santillán**

Samuel Jouault***

\section{Resumen}

Este texto aborda, en sentido diacrónico (siglos XX y XXI), lo que consideramos un importante proceso socioterritorial. La intención es analizar las transformaciones en 19 manzanas del barrio de Santiago, en el centro histórico de la ciudad de Mérida, Yucatán. Para tales efectos, consideramos elementos de cambio relacionados al estado fisico del patrimonio construido, a su uso, al tipo de residentes, así como a otros aspectos que tocan lo sociocultural, lo económico y lo político. Desde una lógica que se replica a escala global, aunque siempre con especificidades locales, discutimos aquí sobre la existencia de un proceso de gentrificación en la zona de estudio.

Palabras clave: gentrificación; residentes extranjeros; barrio de Santiago; procesos socioterritoriales.

* Universidad Autónoma de Yucatán, Centro de Investigaciones Regionales. Dirección: Calle 61, col. Centro, Mérida, Yucatán, 97500, México. Correo: claudia.davila@correo.uady. mx ORCID: https://orcid.org/0000-0002-7636-2695

** Universidad Nacional Autónoma de México, Centro Peninsular en Humanidades y Ciencias Sociales. Dirección: Calle 43 s/n, col. Industrial, 97150, Mérida, Yucatán, México. Correo: ricardo_lopezsantillan@yahoo.com.mx ORCID: https://orcid.org/0000-0003-08884819

*** Universidad Autónoma de Yucatán, Facultad de Ciencias Antropológicas. Dirección: Carretera Mérida-Tizimín, Km 1, Cholula, 97305, Mérida, Yucatán, México. Correo: samuel. jouault@correo.uady.mx ORCID: https://orcid.org/0000-0003-4419-900X 


\begin{abstract}
This text diachronically addresses (in the 20th and 21st centuries) what we regard as an important socio-territorial process. It seeks to analyze the transformations of 19 blocks in the Santiago neighborhood, in the historic center of the city of Mérida, Yucatán. To this end, we consider elements of change related to the physical state of the built heritage, its use, the type of residents, as well as other aspects that touch on sociocultural, economic and political aspects. From a logic replicated on a global scale, albeit always with local specificities, we discuss the existence of a gentrification process in the study area.
\end{abstract}

Keywords: gentrification; foreign residents; Santiago neighborhood; socioterritorial processes.

\title{
Introducción
}

Hoy en día, a escala nacional e internacional, la ciudad de Mérida, capital de Yucatán, es un referente de una vida apacible y sin sobresaltos en el sureste mexicano. Varios son los factores que la vuelven atractiva, como el nivel de equipamiento urbano o el hecho de ser una de las localidades más seguras del país (lo que resulta insoslayable en un contexto de violencia casi generalizada). En lo que respecta a la cuestión económica o, mejor dicho, a las formas sociales de la economía (Bourdieu, 2000), el nivel de precios de los bienes inmuebles, y de la ciudad en general, permite que ciertos sectores de clase media alta y algunos grupos de élite hagan negocio o den valor agregado a su patrimonio de manera sencilla y segura.

No se puede desdeñar, tampoco, el valor estético arquitectónico e histórico de la vivienda en una ciudad de gran belleza. Mérida, además, destaca por tener uno de los centros históricos más grandes del país, caracterizado en buena medida por edificaciones de corte neoclásico y ecléctico que le han dado una identidad que los expertos califican de "señorial" (Peraza Guzmán, 2012, p. 44). Todos estos valores le han permitido mostrarse al mundo con una imagen de ciudad con historia, atractiva por las edificaciones de su centro histórico y auténtica porque posee un gran patrimonio cultural, herencia del pasado prehispánico maya. Los gobiernos estatal y municipal han utilizado esta imagen para fomentar el turismo, que para Mérida ha sido sobre todo el turismo de congresos, el así llamado premium, y el de segunda residencia.

El centro histórico de la ciudad se encuentra dividido por cuatro cuarteles que rodean la Plaza Mayor y cinco barrios: La Mejorada, Santa Ana, San Cristóbal, San Sebastián y el que nos ocupa en esta investigación, el de Santiago. La intención aquí es analizar algunas de las transformaciones que han tenido lugar desde el siglo XX hasta nuestros días, específicamente en 
19 manzanas que se localizan en el céntrico barrio de Santiago. Las transformaciones de las que daremos cuenta están relacionadas con cambios socioculturales, de escala económica y política que van más allá del ámbito local o regional, y es que, lejos de ser un caso anómalo, es uno de tantos que se están presentando en los centros históricos de las ciudades mexicanas, sobre todo en las ciudades medias.

En cuanto a la metodología, además de la revisión bibliográfica y cartográfica, hicimos una serie de recorridos por la zona, así como entrevistas semiestructuradas tanto a yucatecos como a extranjeros que residen en nuestra área de estudio. Cabe señalar que, por razones de protección de su identidad, nuestros informantes serán llamados sólo por su nombre de pila, y para aquellos que no consintieron la utilización de su nombre, recurrimos a un seudónimo. In situ hicimos un catálogo de las casas y de sus características, más específicamente, de las 19 manzanas que escogimos como zona de estudio. Nos apoyamos igualmente en los datos que proporciona el INEGI en su página de internet.

Para los propósitos referidos presentamos tres apartados en los que detallamos, de manera diacrónica, las transformaciones del lugar. El primero hace un recuento histórico del barrio durante el siglo XX, que va del auge al progresivo abandono. El segundo apartado analiza la situación actual del barrio y de las 19 manzanas que escogimos para nuestra pesquisa, lo que permite dar cuenta de la progresiva revitalización de esa parte de Santiago. Finalmente, en el tercer apartado, discutimos sobre la presencia de un proceso de gentrificación que, si bien no es generalizado para todo el centro histórico, en el barrio que nos ocupa sí es posible encontrar algunas zonas inmersas en este proceso.

\section{El barrio de Santiago durante el siglo XX}

Desde el periodo posrevolucionario, los barrios del centro de Mérida quedaron bastante bien diferenciados a nivel social; quizá sea ésta una de las características que se han mantenido de forma más evidente hasta nuestros días. Los sectores medios se establecieron en el poniente y oriente, muy al margen de los sectores marginados del sur, mientras que a las clases altas se les ubicó en el norte (Peraza Guzmán, 2012, p. 45). Es durante este periodo en el que se construyó, por lo menos para los cuarteles, la mayor parte de los edificios, a saber, el 34\% de los mismos (Ballina Viramontes, 2007). El indudable valor urbano, estético y arquitectónico del centro histórico de Mérida data de esa época. En general, los inmuebles edificados en este periodo son "pequeños, medianeros y alargados, de estrechas dimensiones al 
frente de la calle, pero extendiéndose generosamente hacia el interior de la manzana" (Ballina Viramontes, 2007, p. 84).

Santiago es un barrio histórico cuya población se congregó alrededor de una de las iglesias más antiguas de Yucatán y que se caracterizó por su población preponderantemente católica y por tenerlo todo cerca. Los relatos recrean un espacio lleno de vitalidad donde no había que desplazarse fuera del barrio para disfrutar todo lo que una ciudad puede ofrecer. Las tandas, la música, los magos y los cómicos se disfrutaban en el teatro Variedades, mientras que en el Circo Teatro Yucateco, ${ }^{1}$ con capacidad para más de tres mil personas, se celebraban corridas de toros, funciones de box, de teatro, espectáculos artísticos y circenses.

En el barrio había también sitios de reunión como los cafés "Flor de Santiago", "Primera Central" y "Café Ideal"; se disfrutaba de espacios muy arbolados como el parque y el zoológico del Centenario; ${ }^{2}$ además se contaba con un mercado, cinco farmacias o boticas, tres cines, el Museo de Historia Natural, la Facultad de Medicina de la Universidad Autónoma de Yucatán (UADY), el Colegio Americano, la escuela Vicente Guerrero, la primaria Nicolás Bravo, un moderno supermercado (el entonces San Francisco de Asís), así como algunas oficinas de gobierno y dos embotelladoras que ya no están en el barrio (Sidra Pino y Coca Cola).

Santiago era un barrio donde la abundante población infantil jugaba en las calles al tiempo que los adultos, por las tardes y noches, se sentaban a platicar o refrescarse en las aceras al frente de la puerta de sus casas. "En sus días floridos [el barrio de Santiago] fue habitado por gente de gran alcurnia, en su mayoría por profesionistas e intelectuales de su época, como doctores y maestros" (Pérez Pérez, 1991, p. 74). Fue lugar de residencia del gobernador Felipe Carrillo Puerto; su otrora casa funge hoy en día como funeraria. La importancia de este barrio radicaba, entre otras cosas, en su tradicional y concurrida feria del 21 de julio al 6 de agosto que, aunque "tenía un motivo religioso, el aspecto profano y comercial era el más llamativo" (Escalante Ceballos, 2016, p. 176). También, Santiago constituía uno de los principales caminos de entrada a la ciudad: era "la ruta al centro de la ciudad, tanto para los viajeros que venían por la carretera de Campeche, como para los que arribaban por la vía aérea" (Escalante Ceballos, p. 194). Paradójicamente, este eje vial dividiría también el barrio en dos.

${ }^{1}$ El Circo Teatro Yucateco ocupaba toda la manzana 19 del Mapa 2. Funcionó de 1900 a 1961. Después fue demolido y en su lugar se construyó una serie de casas con el típico estilo arquitectónico de las décadas de 1960 y 1970, la mayoría de dos pisos.

${ }^{2}$ Inaugurado por Porfirio Díaz, su nombre hace alusión a la celebración del centenario de la Independencia de México. 
Hasta la fecha no es posible trazar los límites exactos del barrio de Santiago, pues todavía "no existe información suficiente, ni acuerdo alguno" para precisar sus fronteras (Reyes Pérez, 2012, p. 29). Lo que al parecer ha sido uno de los factores clave para la delimitación del barrio es la cuestión identitaria, y así lo encontramos en diferentes tesis de licenciatura de la Facultad de Arquitectura de la Universidad Autónoma de Yucatán (UADY) que tratan sobre el rescate integral de este barrio. En dichos trabajos se asegura que, conforme el radio de acción de la iglesia se aleja de las viviendas, los habitantes cada vez menos se identifican con el barrio, por lo que estas tesis establecen las demarcaciones "de acuerdo a una delimitación eclesiástica y por sentimiento de pertenencia". Para esta investigación tomamos en cuenta los límites de estos trabajos, por lo que la delimitación del barrio quedaría de la siguiente manera: al norte el límite sería la calle 47, al sur la 69, al oriente la 66 y al poniente la 86 (véase el Mapa 1). Sin embargo, es preciso aclarar que este estudio se concentra en una zona más pequeña, que describiremos más adelante.

En el estado de Yucatán, durante el periodo de modernización funcionalista de la década de 1950, comenzó un proceso acelerado de urbanización que consistió en que más de la mitad de la población abandonó el sector primario de la economía para convertirse en población citadina empleada en el sector servicios. De esta manera, se inició un proceso de crecimiento urbano que no se generó sobre la base de un desarrollo industrial; por el contrario, se registró sobre todo la especialización en el sector comercio y servicios, concentrada particularmente en la ciudad de Mérida (Ramírez, 1993, p. 66). Como parte de esta evolución, se observa que zonas importantes del núcleo central de la urbe terminaron por terciarizarse y especializarse en el abasto. Este proceso trajo como resultado la expulsión de una buena parte de la población del centro histórico de la ciudad de Mérida (véase Peraza Guzmán, 2012, p. 46).

Esta transformación incluso tuvo eco a nivel gubernamental, pues los planes de desarrollo de la década de 1970 dejaron de concebir al centro de la ciudad como una zona residencial, para considerarla preponderantemente de comercios y de servicios. Comenzó un periodo de abandono en el que las nuevas generaciones fueron perdiendo el arraigo al centro histórico. Así, durante la segunda mitad del siglo XX, se registró una paulatina migración de los habitantes del centro hacia la periferia moderna en el norte, donde se generaron nuevas áreas habitacionales dotadas de un equipamiento tan completo que llegaron a descentralizar incluso algunos de los servicios 


\section{Mapa 1}

Barrio de Santiago
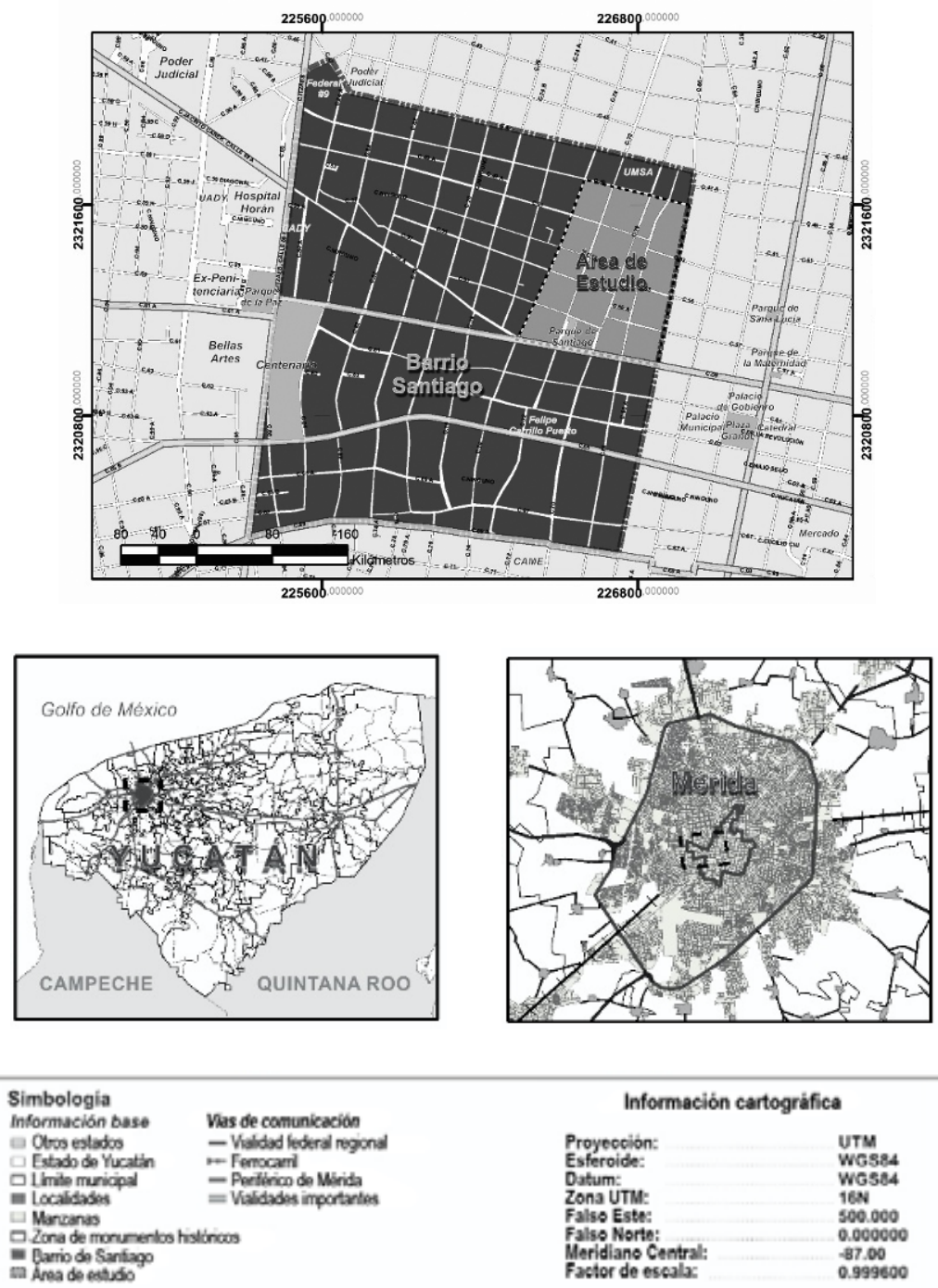

Información cartogräfica

$\begin{array}{ll}\text { Proyeccion: } & \text { UTM } \\ \text { Esferoide: } & \text { WGS84 } \\ \text { Oatum: } & \text { WGS84 } \\ \text { Zona UTM: } & 16 N \\ \text { Falso Este: } & 500.000 \\ \text { Falso Norte: } & 0.000000 \\ \text { Meridiano Central: } & -87.00 \\ \text { Factor de escala: } & 0.999600\end{array}$

Fuente: Elaboración propia con datos del INEGI, 2016. 
(López Santillán, 2011; Iracheta y Bolio, 2012). ${ }^{3}$ Sin embargo, este desarrollo y crecimiento de Mérida no sería homogéneo, pues la población radicada al sur, sur oriente y sur poniente de la ciudad no contó con la desconcentración de los servicios, por lo que el centro histórico continuó, hasta nuestros días, con su papel de principal área de consumo, abasto y dotación de servicios de los sectores populares.

El centro histórico fue una de las zonas con mayores transformaciones dentro del proceso de urbanización de la segunda mitad del siglo XX, que terminaría con una marcada terciarización de la economía y de la geografía de la zona. Peraza Guzmán (2012, p. 47) asegura que, durante tres décadas, el centro experimentó la "mayor depredación de sus inmuebles históricos"; refiere que un tercio del total de los predios sufrieron transformaciones modernizadoras de corte funcionalista. En entrevista, el referido autor nos comentó que alrededor de la mancha comercial había un círculo de viviendas abandonadas que entraron en un muy largo proceso de especulación que hacía que los precios bajaran mucho porque no había gente habitándolas. Esta dinámica generó entonces el uso de muchos predios como bodegas o estacionamientos, ${ }^{4}$ mientras que otras zonas se convirtieron en áreas olvidadas e incluso inseguras. En lo que respecta al barrio de Santiago, el cronista Felipe Escalante cuenta que fue testigo del éxodo de algunos de sus amigos y de su propia familia, seguido del cierre de farmacias, del Teatro de Variedades, del Circo Teatro Yucateco, del incendio del cine Rialto, así como de la aparición de semáforos en la calle 59: "sin duda, el encanto del viejo barrio mermaba a ojos vistas" (Escalante Ceballos, 2016, p. 291).

Para la década de 1980, Yucatán registró cierto crecimiento económico gracias a la revitalización del comercio, lo que provocaría algunas transformaciones de los hábitos y formas de consumo de sus habitantes, particularmente los de Mérida, su capital. Ramírez (1993, p. 88) afirma que desde entonces comenzó a desarrollarse una cultura más "citadina" que provocaría un híbrido cultural, entendido éste como "un habitante urbano con una fuerte herencia cultural del mestizaje maya-español y un acentuado proceso de identificación con imágenes y formas de consumo occidentales". Los habitantes del centro histórico, y en particular los del barrio de Santiago, no

\footnotetext{
${ }^{3}$ Iracheta y Bolio (2012) refieren que se dio un mayor crecimiento urbano, de dotación de servicios de calidad y generación de plusvalías al norte de la ciudad, en buena medida por la concesión de tierras de la reserva territorial del estado (en algunos casos, para el pago de favores políticos); o bien, a través del cambio de tierra ejidal a propiedad privada con fines de construcción de vivienda de clase media, a través del Programa de Certificación de Derechos Ejidales y Titulación de Solares.

${ }^{4}$ Entrevista con Marco Tulio Peraza Guzmán en Mérida, 11 de julio de 2018.
} 
fueron ajenos a esta dinámica de la población urbana de todo el estado. En este afán modernizador, entre 1982 y 1985, el entonces alcalde de Mérida "ordenó modificar la estructura de la plazoleta santiaguera para formar cajones de estacionamiento de vehículos automotores" (Escalante Ceballos, 2016, p. 183). De esta manera se pondría fin a la tradicional feria de Santiago para quedar como uno de los recuerdos de los que viven o vivieron en el barrio. Así, Mireya asegura que hay gente que dice "cómo no la vuelven a hacer", pero el problema es que "nadie pone ayuda". 5

Es justo durante esta década cuando el gobierno federal comenzó a considerar la importancia de preservar el patrimonio histórico arquitectónico de las ciudades. Para el caso de Mérida, se publicó en 1982, en el Diario Oficial de la Federación, el decreto por el que se declara una extensa zona de monumentos históricos. Se contabilizaron un total de 3906 edificios con valor histórico en 659 manzanas, de los cuales 21 fueron destinados en alguna época al culto religioso; otros 47 corresponden a inmuebles con fines educativos, asistenciales o de gobierno. Los más de 3800 edificios restantes eran inmuebles civiles de uso particular que tenían elementos arquitectónicos y detalles ornamentales que, según el decreto, definían un "verdadero estilo regional".

Hacia la última década del siglo XX encontramos algunos trabajos académicos que ubican al centro histórico de Mérida dentro de una problemática de despoblamiento, abandono y terciarización. En lo que se refiere específicamente al barrio de Santiago, en la biblioteca de la Facultad de Arquitectura de la UADY se encuentran las ya referidas tesis de licenciatura que datan de 1991 y que plantean como objetivo principal el "rescate integral del barrio de Santiago". En estas tesis se elabora todo un diagnóstico de la problemática, la cual va más allá de la vocación económica del barrio o del uso de sus edificios. Uno de los supuestos más socorridos en estos trabajos es que el deterioro y el abandono de las décadas precedentes estaban generando cambios en la identidad y las costumbres del lugar. El desarraigo de la población y el cambio en las funciones y usos de las edificaciones se sumaría al paulatino abandono de éstas. Los usos comercial e industrial comenzaban a ganar importancia.

Es importante destacar que esta serie de productos escolares y académicos que diagnosticaban la pérdida de habitantes y de vitalidad del barrio, así como el deterioro de sus edificaciones, se llevó a cabo unos años antes de que comenzara el flujo de inmigración extranjera a la zona que se registra hoy en día. Como ejemplo de lo señalado, Roberto Reyes Pérez (2012, p.

\footnotetext{
${ }^{5}$ Entrevista con Mireya en el barrio de Santiago, 17 de octubre de 2018.
} 
2) asegura en su tesis que el barrio de Santiago fue, durante mucho tiempo, objeto de continuas transformaciones tanto en su arquitectura como en sus funciones, y asegura también que en cierta forma se perdió su carácter de barrio debido justamente al abandono y a su consecuente deterioro.

Por su parte, ya a inicios del siglo XXI los especialistas seguían haciendo hincapié en la problemática del centro histórico, lo que en palabras de Ballina Viramontes (2007b, pp. 103-104) se sintetiza en un proceso de "destrucción, terciarización y abandono", de gradual deterioro de los inmuebles, de los espacios públicos, con áreas deshabitadas y zonas muertas en horarios no comerciales.

\section{El barrio de Santiago en la era de la globalización}

Los barrios del centro histórico de la ciudad de Mérida que experimentaron una intensa edificación durante la época posrevolucionaria, para finales del siglo XX presentaban un descenso paulatino en su uso residencial pues mucha de la población joven y adulta de Mérida no encontró mayor interés en permanecer o rehabilitar sus propiedades ubicadas en las zonas céntricas. El costo del mantenimiento, así como las adecuaciones que se imponen por las formas de vivir actuales, hicieron que muchas familias optaran por mudarse a casas recién construidas (Ballina Viramontes, 2007b, p. 104). En medio de este proceso de desplazamiento residencial se presentó también otra de las transformaciones que ya habíamos mencionado: la terciarización, y es que algunos de los habitantes de Santiago cambiaron sus actividades y con ellas su sentir hacia el barrio (Pérez Pérez, 1991, p. 73).

Con el comienzo del siglo XXI y la incorporación de la región a dinámicas socioeconómicas y culturales más modernas y de alcance global, iniciaron algunas importantes transformaciones dentro del centro histórico de la ciudad, y en particular dentro del barrio que aquí nos ocupa. Tales cambios se derivaron de la llegada de población extranjera. Es importante mencionar que hasta antes del nuevo siglo, según Ramírez (2006, p. 75), en Mérida no había un movimiento migratorio masivo, pues gran parte de los que venían eran yucahuaches, es decir migrantes nacionales, incluso muchos de ellos con padres o abuelos yucatecos. Mérida nunca registró una migración de obreros ni proletarios desempleados, sino que, a finales del siglo XX, la ciudad se había convertido en un destino de una pequeña migración de clase media que, por lo general, venía con trabajo y que por sus características socioeconómicas resultaban muy visibles (Ramírez, 2006; Pérez Campuzano y Gamallo, 2014). 
Con la llegada del nuevo siglo, vino a sumarse la también visible migración de extranjeros. Cabe destacar que este tipo de migración, contrario a la que se deriva por problemas económicos, por conflicto o persecución política, no implica una separación dolorosa de la patria; al contrario, tiene algo de lúdica o de aventurera. Recordemos que el fenómeno migratorio es multifacético y presenta varias modalidades. En la era de la globalización se encuentra aquella en donde algunos países periféricos, como México, se han convertido en receptores de cierto tipo de población extranjera que decidió cambiar su lugar de residencia. Se trata de un movimiento al que llamaremos lifestyle migration ${ }^{6}$ (Benson y O'Reilly, 2009), en el que personas de todas las edades, que generalmente pertenecen a las clases medias de países industrializados, deciden irse de manera individual al extranjero, por temporadas o de forma permanente, con el fin de encontrar una vida más significativa y relajada. En general, son personas que se caracterizan por la posesión de cierto capital económico y de algunos privilegios como la libertad de movimiento; además tienen un imaginario propio que se construye, entre otras cosas, gracias a la posesión de un cierto capital cultural que pone de relieve nuevas preferencias en su consumo. ${ }^{7}$

Según el estudio de Promatura, para 2008, a los extranjeros radicados en Mérida se les caracterizaba como gente en la que predominaban los adultos en edad avanzada. La mitad correspondía a migrantes retirados y el $44 \%$ trabajaba medio tiempo o tiempo completo. El 6\% restante, según el estudio, no recibía remuneraciones por las labores que desempeñaban (citado en Reyes Pérez, 2012, p. 50). Para 2010, según el Censo de Población del INEGI, los extranjeros en Yucatán representaban sólo el $0.35 \%$ del total de la población. Lo interesante aquí es que podemos observar cierta tendencia al alza respecto a la registrada en los dos censos anteriores (1990 con el $0.14 \%$ y 2000 con el $0.21 \%$ ). Según los datos, el crecimiento porcentual de Yucatán como receptor de población extranjera entre los años 2000 y 2010 fue del $92.1 \%$, de suerte que la llegada de estadounidenses creció $68 \%$, y la de los europeos 53\%. Aunque en términos absolutos la presencia no es significativa, la tendencia en los primeros diez años del siglo XXI fue de crecimiento de la población extranjera residente en terri-

${ }^{6}$ A la migración Norte-Sur se le ha llamado de diversas maneras y se le ha tratado desde diferentes perspectivas. Algunos ejemplos son: turismo de segunda residencia, turismo internacional de retiro, turismo sénior, turismo residencial / migración residencial, migración de jubilados. Nosotros decidimos trabajar desde la perspectiva teórica que se ha desarrollado alrededor del concepto lifestyle migration pues consideramos que resulta más abarcativa en la medida en que toma en cuenta a migrantes de todas las edades y no sólo a los jubilados, así como a los que migran por temporadas y los que migran en forma definitiva.

${ }^{7}$ Aquí usamos los conceptos relativos al capital en el sentido expuesto por Bourdieu, 1979. 
torio yucateco. Al día de hoy se contabilizan más de 5500 extranjeros en la ciudad de Mérida.

En esta dinámica global, podemos observar que Mérida y en especial algunos de sus barrios localizados en el centro histórico - como el de Santiago, que aquí nos ocupa- se encuentran hoy en día en medio de importantes transformaciones que se combinan al mismo tiempo con muchas continuidades. Por un lado, se mantiene la existencia de ese centro con un sector comercial pujante, desordenado e invasivo. Por otro lado, siguen ahí los antiguos residentes, los de las familias yucatecas (muchas de ellas de edad avanzada) que no han querido abandonar sus casas ni dejar el centro de la ciudad, y que en su mayoría son jubilados, comerciantes en activo, empleados públicos o profesionistas. En fin, son personas que, a pesar de la baja de sus niveles de vida atribuida a la edad, todavía pertenecen a las clases medias de Mérida. Por último, encontramos esos nuevos residentes, en su mayoría extranjeros, que adquieren, remodelan y habitan las antiguas casonas, propiciando uno de los cambios más visibles de la zona en los últimos años.

Entre los antiguos residentes yucatecos, muchos de los que nacieron en el barrio de Santiago decidieron salirse del centro, durante la segunda mitad del siglo XX, para adoptar nuevos estilos de vida y viviendas con otras características relacionadas con parámetros de confort diferentes. A decir de Mireya, una de nuestras entrevistadas, los jóvenes se fueron y los mayores se quedaron. Nos explica que entre los vecinos de antaño, hay a quienes ya no se les ve porque se han ido muriendo, aunque también reconoce que hay algunos pocos a los que sus hijos se los han llevado a vivir con ellos. ${ }^{8}$ La dinámica es que, después de que se fueron los pobladores locales, poco a poco han ido llegando nuevos residentes, en su mayoría procedentes del extranjero. Sin embargo, resulta paradójico que los nuevos residentes llegan a vivir al barrio buscando lo mismo que aquellos que se fueron: confort y calidad de vida.

Los que llegaron descubrieron las ventajas de la zona, las mismas que se encontraban en aquellos años de esplendor, es decir, bienestar en el sentido amplio del término. Son esas ventajas que aún hoy en día encuentran algunos de los yucatecos que ahí residen, como opina el entrevistado de la farmacia homeopática Colomé, quien resalta:

Aquí tienes todo [...] Yo de aquí jamás me movería, tengo todos los teatros. A tres esquinas tienes súper [mercado], tienes mercado [municipal], tienes restaurantes, tienes cine, tienes la iglesia, o sea todo, todo, todo. ${ }^{9}$

${ }^{8}$ Entrevista con Mireya en el barrio de Santiago, 17 de octubre de 2018.

${ }^{9}$ Entrevista con Colomé en el barrio de Santiago, 19 de octubre de 2018. 
Ciertamente, la llegada de los extranjeros al centro histórico de Mérida, y en particular al barrio de Santiago, ha abonado a la revalorización de un espacio que se encontraba en proceso de deterioro. El fenómeno ha tenido un perfil relacionado con la calidad de vida de la zona.

Es importante señalar que, en general, los migrantes extranjeros están bastante bien enterados de en dónde van a instalar su nuevo lugar de residencia, ya sea con carácter permanente o temporal. La decisión no se hace al azar, sino que hay toda una suerte de oferta informativa en publicaciones impresas o electrónicas, además de las redes de amistad y de solidaridad entre amigos o familiares que ya residen en Mérida. En estos procesos el internet ha sido fundamental, incluso tratándose de personas mayores, pues constituye una fuente primordial de información tanto para la elección como para cuestiones prácticas. La información disponible en línea permite al migrante tomar decisiones ventajosas. Greenwood, nuestro entrevistado, nos comenta que tiene algunos amigos de Nueva York que han venido porque en el New York Times leyeron varios anuncios sobre Mérida. En cuanto a su propia experiencia migratoria nos dice: "Hice una lista de lo que quería y dónde quería vivir, porque quería vivir simple [...] quería vivir en un lugar en donde no tuviera que tomar el carro", por lo que él y su esposa comenzaron a visitar varios lugares. Al llegar a Mérida, un amigo ya residente les mostró una casa:

La vimos y dijimos ¡wow perfecta!, jésta es, ésta es! Entonces hicimos los arreglos y regresamos y nos deshicimos de todo, todo. Teníamos dos maletas, un kayak, mi perro en mi jeep y unos pocos meses después, seis meses después, vinimos y este octubre cumplí 10 años [viviendo en Mérida]. ${ }^{10}$

Dado que el barrio de Santiago es muy extenso en términos de área, para los fines de esta investigación nos concentrarnos en 19 manzanas (véase el Mapa 2). Son las que se encuentran entre las calles 49 al norte y 59 al sur, y entre la 66 al oriente y 74 al poniente. Escogimos esta zona por varias razones: es el corazón de Santiago, pues incluye las manzanas donde se encuentra el mercado municipal, la iglesia, el parque y el cine Rex (que aún funciona, ya como franquicia de Cinemex). En esta zona de estudio es donde también se encuentra la Mérida English Library, que constituye un bastión importante para la comunidad de residentes extranjeros angloparlantes, pues con sus eventos los convoca con mucha frecuencia. En esta área también se concentran varias calles de casas remodeladas que se unen con

${ }^{10}$ Entrevista con Greenwood en el barrio de Santiago, 23 de junio de 2017. 
otras del barrio de Santa Ana y que conforman lo que los propios residentes extranjeros y ahora también los locales, han llamado el Gringo Gulch.

\section{Mapa 2}

Zona de estudio en el barrio de Santiago

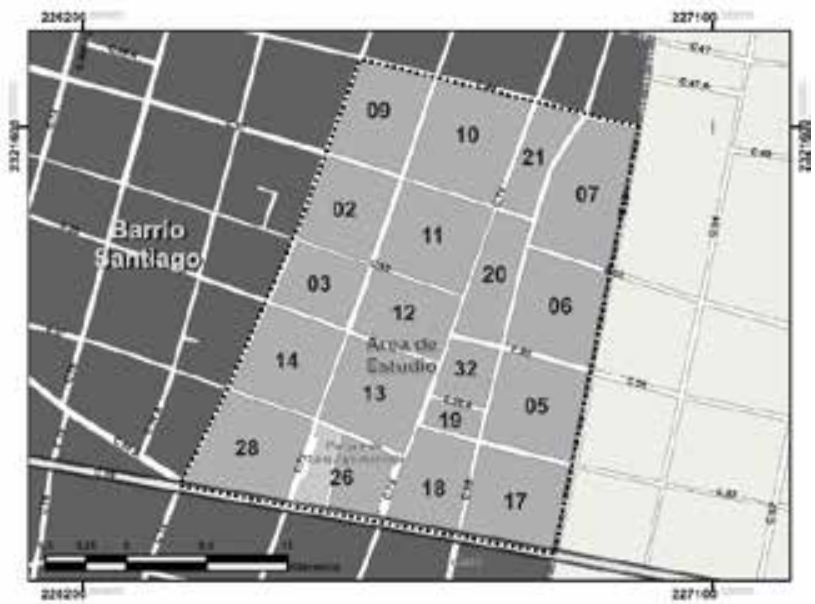

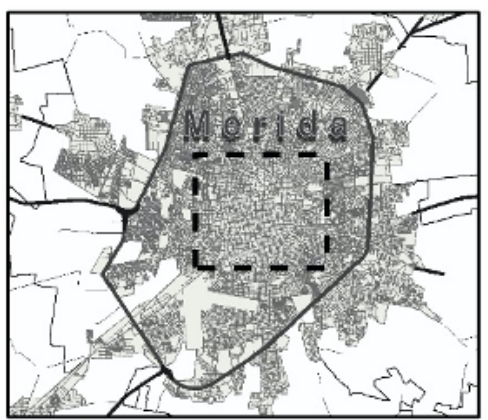

Simbologia información base

cis Cos estados

$\square$ Extado de Yucatín

$\square$ I imite muricipal

E Localidades

- Marcanas

- Zona de monumentos hislíncos

- Bario de Santago

a Anea de estudio

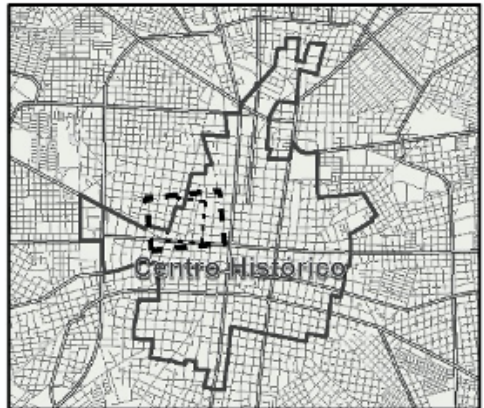

Información cartográfica

$\begin{array}{ll}\text { Proyeccion: } & \text { UTM } \\ \text { Esferoide: } & \text { WGS84 } \\ \text { Datum: } & \text { WGS84 } \\ \text { Zona UTM: } & 16 N \\ \text { Falso Esta: } & 500.000 \\ \text { Falso Norte: } & 0.000000 \\ \text { Meridiane Central: } & -87.00 \\ \text { Factor de escala: } & 0.999600\end{array}$

Fuente: Elaboración propia con datos del INEGI, 2016. 
En el Cuadro 1 podemos observar algunos aspectos que es preciso destacar aquí, como el hecho de que el barrio de Santiago es una zona que se caracteriza todavía por ser, sobre todo, habitacional. Un aspecto que salta a la vista es que el $39.23 \%$ de los que residen en esta zona tienen más de 60 años, y esto incluye tanto a los yucatecos como a los nuevos residentes. En nuestras 19 manzanas, a excepción de la zona comercial que rodea el mercado (manzana 26), son pocos los establecimientos económicos en comparación con el número de casas. Según los datos que proporciona el INEGI, el 44.05\% de las casas están deshabitadas; sin embargo, esto no quiere decir que todas estén abandonadas o en mal estado. Muy por el contrario, hay algunas que están remozadas y completamente equipadas. Dos son las posibles explicaciones: la primera se relaciona con los propietarios extranjeros que viven en la ciudad una temporada al año, casi siempre en los meses frescos (en otoño e invierno), y la segunda, con el hecho de que algunas de estas casas están destinadas para ser rentadas en plataformas como Airbnb o Booking.

En las 19 manzanas que abarca nuestro estudio, encontramos que 67 casas ofrecen servicios de Airbnb (véase el Mapa 3), ${ }^{11}$ ya sea la casa completa o la renta de alguna habitación. Se puede observar que los extranjeros han remodelado y puesto en renta muchas de las casas de este barrio. La variedad y los precios son considerables, sin embargo, pudimos notar que las mejores casas en términos de remodelación, servicios y mobiliario pertenecen a extranjeros. De las 67 casas que encontramos, se puede saber con certeza que $28,{ }^{12}$ es decir el $41 \%$, pertenecen a extranjeros; sin embargo, este porcentaje puede ser mayor, pues seis casas son administradas por una empresa de nombre Remixto ${ }^{13}$ y otras tres por otra llamada Burro y Flauta Vacation Rentals. ${ }^{14}$ Tres son hoteles: Viva Mérida, Zamná y Santiago 57. Resalta igualmente el hecho de que también encontramos gente de origen yucateco que renta a través de esta plataforma, la mayoría de ellos alguna habitación y unos cuantos la casa completa; es decir, estas nuevas dinámicas han abierto oportunidades incluso para los antiguos residentes locales.

${ }^{11}$ Estos datos fueron sacados de la plataforma electrónica de Airbnb durante los meses de septiembre y octubre de 2018. Es importante tener en cuenta que esta información varía mucho de un día para el otro, pues notamos que hubo algunas casas que desaparecieron mientras que otras más se incorporaron.

${ }^{12}$ Se trata de 18 estadounidenses, cuatro canadienses, tres ingleses, un alemán, un italiano y uno islandés.

${ }^{13}$ Remixto es una empresa que se encuentra en la ciudad de Mérida, fundada por dos extranjeros. Se encarga de rentar y cuidar más de cuarenta casas en la región. Véase www. remixto.com

${ }^{14}$ Burro y Flauta es una empresa fundada por "expats que hicieron de Mérida su casa" y, al igual que Remixto, se encarga de rentar y cuidar propiedades en Mérida. En su página se anuncian siete y todas localizadas en el centro histórico de Mérida. Véase www.burroyflauta.com 


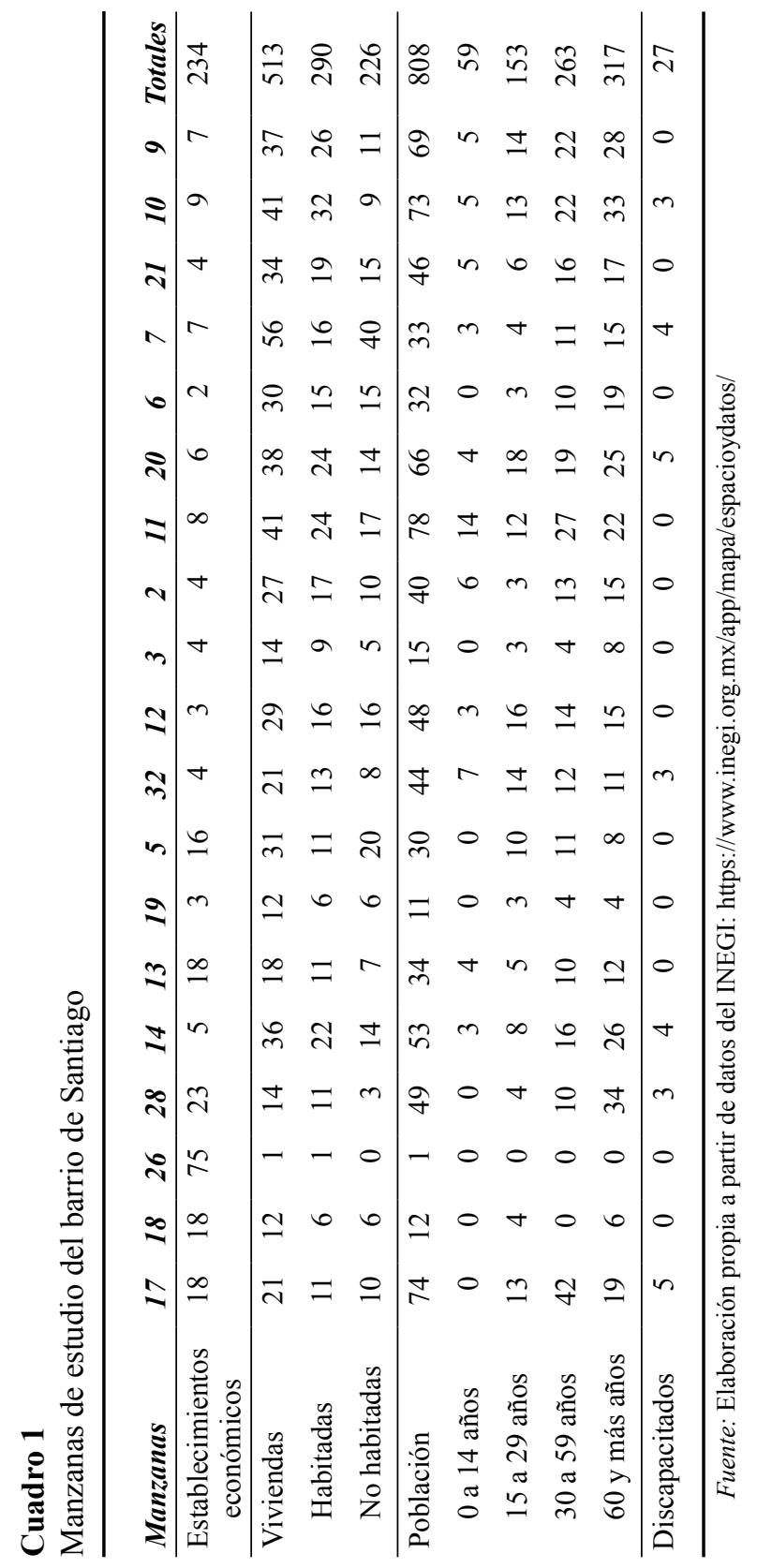




\section{Mapa 3}

\section{Oferta Airbnb en la zona de estudio}
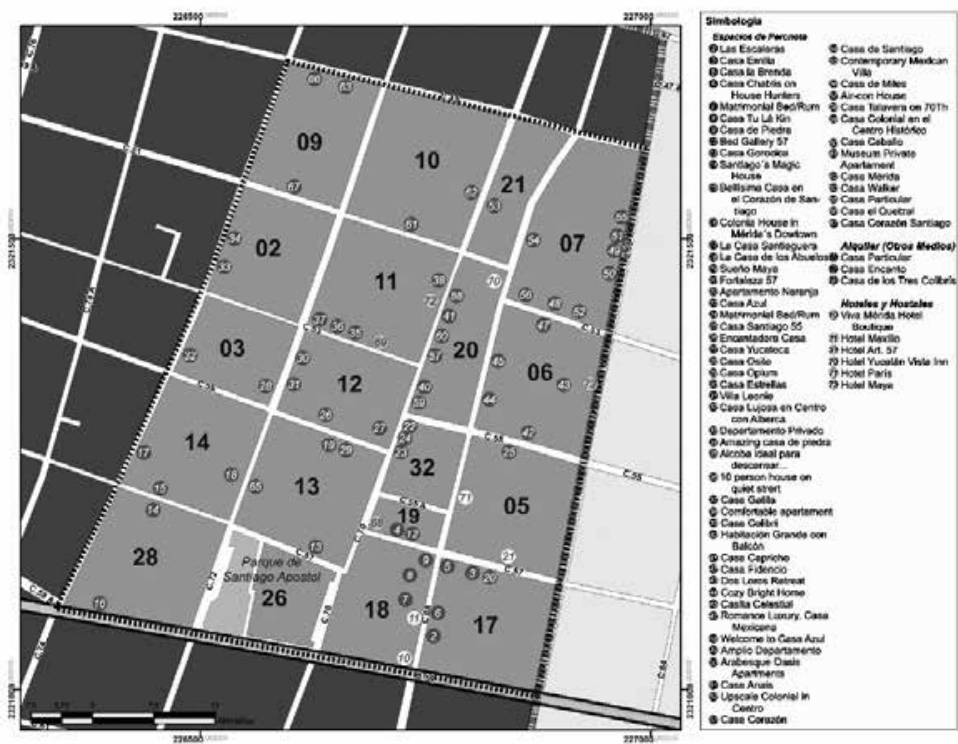

Fuente: Elaboración propia con datos de la página electrónica de Airbnb, disponible en https://www.airbnb.mx (datos obtenidos en septiembre y octubre de 2018).

\section{Proceso de gentrificación ${ }^{15}$ en el barrio de Santiago}

El concepto de gentrificación, según la definición de Ruth Glass, se refiere al:

[...] reemplazo de la población existente en un área central de una ciudad, por otros habitantes de mayor nivel de ingresos, lo que lleva a una recomposición

${ }^{15}$ Utilizamos el término gentrificación que, si bien tiende a ser polisémico, es el más socorrido. Aquí nosotros lo equiparamos a otros conceptos, también usados en castellano, que apelan al aburguesamiento, recualificación social o aristocratización de ciertos espacios residenciales. Ninguno de éstos, debemos precisar, es lo suficientemente claro en su conceptualización. Stricto sensu, lo gentry apela a cierta nobleza que no existe fuera de Inglaterra; la aristocratización refiere a "los mejores", o a una clase, también noble, que hereda el poder (según la Real Academia de la Lengua Española); la recualificación social parece un término que pone también énfasis en las "cualidades" de los nuevos pobladores. En ningún caso se puede obviar cierta polémica, por ello apelamos a la categoría analítica que se ha replicado en más textos académicos y por ser la que mejor se apega a los propósitos analíticos de nuestro escrito. 
social, pero también de actividades de las áreas afectadas por el proceso [citado en Hiernaux y González, 2014, p. 7].

Es decir, la gentrificación es un proceso que se ha relacionado fuertemente con la llegada de población de clase media o media alta a vecindarios venidos a menos en los centros urbanos.

En los países anglosajones, la gentrificación se encuentra presente desde hace ya algunas décadas. Son varios los investigadores que han dado cuenta de cómo algunas zonas centrales de algunas ciudades se han visto sometidas a la apropiación y recolonización por parte de personas con cierto poder adquisitivo. Las transformaciones que se registran en dichos espacios los convierten en una opción residencial que de alguna manera termina por reproducir el habitus (Bourdieu, 1979) de los que ahí se instalan. Un proceso al que Allen Scott le ha llamado "elitización residencial" (2007, p. 205), en donde las zonas céntricas ofrecen un estilo de vida urbano y destaca un fácil acceso al trabajo, al ocio y a las actividades culturales.

Sin embargo, el fenómeno que aquí analizamos está lejos de insertarse en la idea anglosajona de gentrificación y es que hoy en día no es posible acotarlo como un proceso único y uniforme. Muy por el contrario, diversas formas y análisis han demostrado la flexibilidad de este concepto. Sólo para mencionar algunas, tenemos la gentrificación rural, studentification, new-build gentrification, supergentrification y a la gentrificación comercial. También tenemos las que resultan más cercanas a nuestro estudio: por un lado, la gentrificación turística de Gotham $(2005 ; 2018),{ }^{16}$ que focaliza el análisis sobre un motor que durante algún tiempo fue ignorado en la gentrificación y que se refiere justamente a la actividad turística. Este tipo de gentrificación resulta característico de las economías periféricas, sobre todo en aquellas donde el turismo se ha convertido en uno de los factores más importantes de desarrollo y crecimiento. Gotham explica que recurrir al turismo para atraer las inversiones urbanas y favorecer la gentrificación ha implicado la mercantilización de lugares por medio de diversas formas de imágenes, símbolos y temas recurrentes. Por el otro lado, tenemos lo que Hiernaux y González (2014) llaman "gentrificación criolla", que pone de relieve justamente la relación entre turismo urbano y gentrificación, en donde el turista, como habitante de los centros históricos, es un agente de producción del espacio tanto material (adquisición de bienes inmuebles) como simbólico, al marcar el área con sus intereses y estilo de vida.

${ }^{16}$ En inglés, tourism gentrification. 
Partimos entonces de la idea de que el proceso de gentrificación no es uniforme ni homogéneo, y ésa es la razón por la que nos interesa establecer aquí algunas de las especificidades del proceso que se encuentran en la zona que abarca nuestro estudio. Ciertamente, la gentrificación en el centro histórico de Mérida resulta incipiente y, si se quiere, tardía, sobre todo si la comparamos con la de otras ciudades donde se presenta este fenómeno. Sin embargo, podemos afirmar que se trata de un proceso que está presente $y$, por la tendencia que se observa, también en crecimiento. Nos interesa destacar el papel que juegan los diferentes actores que han dinamizado el proceso de gentrificación en nuestra área de estudio. En primer lugar, mencionaremos al gobierno a través de algunas políticas públicas como la revitalización y la turistificación de la zona. En segundo lugar, están los sectores de población nuevos que llegan a vivir al centro de la ciudad, y finalmente están los diferentes empresarios que invierten en inmuebles, hoteles, restaurantes, bares, tiendas etcétera.

El proceso de gentrificación de algunas partes del centro histórico de Mérida, como es el caso de nuestra zona de estudio, es resultado de una política pública de los gobiernos estatal y municipal que ha promovido la región, resaltando la belleza del entorno y el valor arquitectónico del patrimonio como parte de una popularizada tendencia a nivel global para atraer recursos financieros. Es una tendencia que insiste en hacer de los centros históricos un punto de atracción, un referente obligado para el ocio, el consumo y el recreo, y es justamente por esta razón que se ha puesto tanta voluntad política y tantos recursos financieros para reembellecer las edificaciones y revitalizar los barrios.

Para abordar más específicamente la ciudad de Mérida y su centro histórico, podemos observar que, en 2008, la Coparmex Mérida organizó un foro regional titulado "Desarrollo de mercado de segunda residencia", donde el entonces secretario de Fomento Turístico de Yucatán dejó claras las intenciones del gobierno estatal para promocionar la llegada de dichos residentes. Posteriormente, el Plan Estatal de Desarrollo 2012-2018 (p. 72) establecía como uno de sus compromisos en el sector turístico "fomentar el turismo de segunda residencia en la ciudad de Mérida"; aseguraba que se trata de "un mercado en expansión y con potencial en el estado, atractivo principalmente para jubilados de Estados Unidos y Canadá". En esta misma lógica, el Programa Especial de Fomento Turístico 2013-2018 (p. 51) también planteó que la llegada de estos extranjeros constituía un área de oportunidad y de desarrollo, y en el Cuarto informe, en 2016 (p. 274), el pasado gobernador del estado aseguró que se había cumplido el $26 \%$ de este compromiso. 
Otra de las implementaciones gubernamentales para volver atractiva la zona céntrica de la ciudad es el Programa Rescate de Fachadas, del Ayuntamiento de Mérida para los inmuebles del centro histórico. Los residentes compran los materiales y el ayuntamiento ofrece, de manera gratuita, mano de obra de los empleados municipales. También resulta paradigmática, en nuestra zona de estudio, la remodelación en 2017 del mercado del barrio de Santiago. Luego de treinta años sin intervenciones mayores, este espacio presenta hoy una imagen de higiene y limpieza que, en palabras del párroco de la iglesia de Santiago, mejoran "la imagen del centro histórico, que atrae cada vez a más visitantes e, incluso, nuevos pobladores". ${ }^{17}$ Nuestro entrevistado, Colomé, tiene la impresión de que el ayuntamiento de Mérida dio capacitación a los vendedores de frutas del mercado de "cómo entregar las frutas como a ellos [los extranjeros] les gusta". ${ }^{18}$

En cuanto a los nuevos residentes, en tanto actores gentrificadores, observamos que se trata de personas que vienen de fuera de Yucatán y en su mayoría de Estados Unidos y Canadá. Una de las especificidades del proceso de gentrificación en nuestra zona de estudio es que no se trata propiamente de una expulsión o desplazamiento de los antiguos residentes por los nuevos. Aquí seguimos la idea expuesta por Sabatini, Robles y Vázquez (2009, p. 18) sobre la gentrificación sin expulsión como una especificidad de ciertas ciudades latinoamericanas, que presentan, sin embargo, dos constantes de la gentrificación: por un lado, la invasión y la consecuente elitización del espacio y, por el otro, la elevación de los precios del suelo. En efecto, en el centro histórico de Mérida se trata más bien de la apropiación y revitalización por parte de los nuevos residentes de algunos de los espacios que habían caído en el deterioro y en el abandono. Es importante destacar que, al menos hasta ahora, es un proceso que no ha terminado, pues aún hoy en día encontramos bastantes casas muy deterioradas y deshabitadas en nuestra zona de estudio.

Bantam-Masum (2015, pp. 6-7) argumenta que las casas grandes del centro de Mérida constituyen un factor central de atracción para los norteamericanos, quienes pueden satisfacer sus aspiraciones de estilo de vida aprovechando las ventajas del tipo de cambio. La autora sostiene que la renovación transforma a las casas clásicas del centro de Mérida en lugares lujosos que simbolizan una nueva forma de vida, es un signo del genio y una ocasión para mostrar diferentes formas de capital. Coincidimos en que

${ }^{17}$ Entrevista hecha al párroco Jorge Carlos Cervera Domani por Reporteros Hoy el 28 de noviembre de 2018. Recuperado de http://reporteroshoy.mx/wp/nuevo-jardincito-estrenaramercado-santiago.html

${ }^{18}$ Entrevista a Colomé en el barrio de Santiago, 19 de octubre de 2018. 
los nuevos moradores del barrio de Santiago tienen altos grados de capital cognitivo, cultural y financiero, de manera que esta comunidad está impulsando cierto boom inmobiliario local y ha desatado la especulación en la zona, donde algunos inmuebles ya se venden en dólares. De hecho, según Bantam-Masum (2015), algunos de los residentes extranjeros se han vuelto compradores, vendedores, agentes inmobiliarios y renovadores. Por ejemplo, nuestra entrevistada María Elena, nacida en Texas, nos cuenta:

Nos vinimos aquí, no con la intención de trabajar ni nada, pero esta casa cuando la vimos, era una destrucción. Yo vi la posibilidad, y me gustan mucho los challenges $[\ldots]$ y yo dije, yo lo voy a hacer. Entonces, yo me hice más o menos la contratista. Yo conocí tanto del trabajo que encontré una pasión en hacer esto de remodelar. ${ }^{19}$

Nuestra área de estudio experimenta, sin lugar a dudas, un proceso de revitalización sobre todo habitacional, pues encontramos algunas calles cuyas casas están, casi en su totalidad, restauradas. Estos cambios son valorados por los mismos residentes yucatecos, como Anita, quien mencionó y resaltó con entusiasmo la limpieza en el entorno, ${ }^{20} \mathrm{o}$ como Colomé, quien nos dijo:

Me gusta todo esto porque, además, con el rescate de las casas que ha hecho la comunidad europea, canadiense y americana, en realidad uno se siente como que vives en un lugar afrancesado [...] toda la vida me ha gustado vivir aquí y ahora más que nunca. ${ }^{21}$

Por su parte, Mireya también nos comentó que sí le gusta cómo se ven las calles: "es bonito porque así ahora ya no entran los borrachitos". ${ }^{22}$

El tercer actor que interviene en el proceso de gentrificación en nuestra área de estudio se sitúa, sobre todo, en el ámbito del negocio inmobiliario y el de servicios. Para nuestra zona de estudio, son aquellos actores que han invertido en la compra- remodelación- venta de casas, en la creación de hoteles y en la amplia oferta de Airbnb (como se muestra en el Mapa 3). Si bien, como ya lo hemos señalado, nuestra área es preponderantemente habitacional, es importante no perder de vista que se encuentra ligada a una zona mucho más extensa, también inmersa en el proceso de gentrificación

\footnotetext{
${ }^{19}$ Entrevista con María Elena en el barrio de Santiago, 23 de junio de 2017.

${ }^{20}$ Entrevista con Anita en el barrio de Santiago, 7 de noviembre de 2018.

${ }^{21}$ Entrevista con Colomé en el barrio de Santiago, 19 de octubre de 2018.

${ }^{22}$ Entrevista con Mireya en el barrio de Santiago, 17 de octubre de 2018
} 


\section{Fotografía 1}

Barrio de Santiago: Calle 66

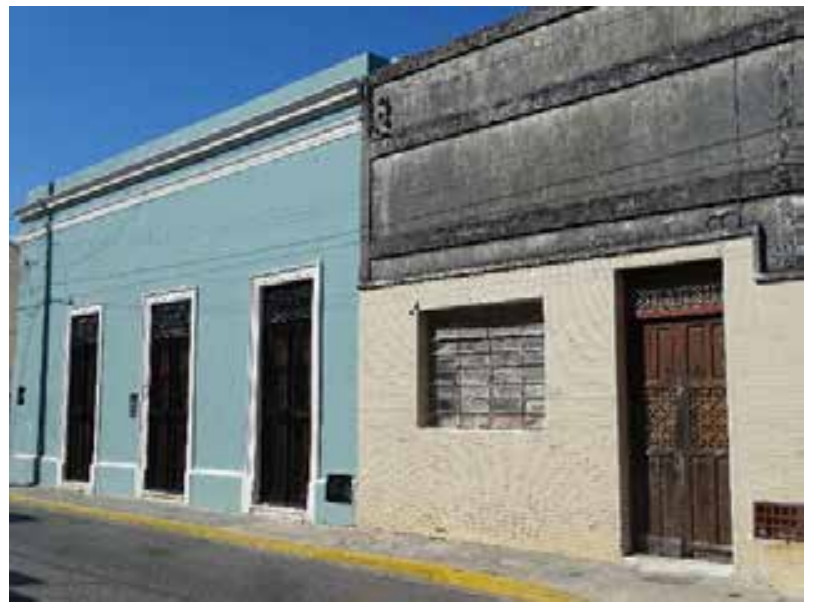

Fuente: Claudia Dávila, octubre de 2018.

\section{Fotografía 2}

Barrio de Santiago: Calle 53

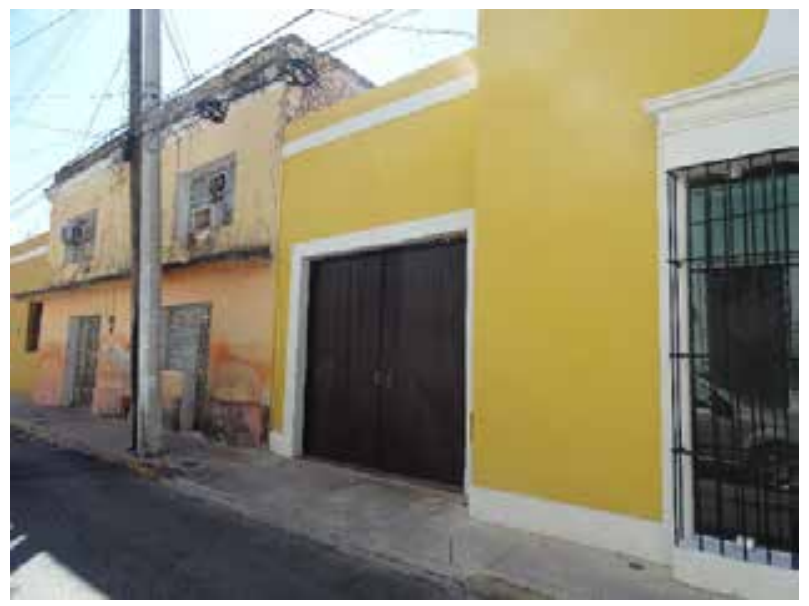

Fuente: Claudia Dávila, octubre de 2018. 
(Santa Ana y Santa Lucía), que le proporciona el fácil acceso y la cercanía con los restaurantes, bares, tiendas de artesanías y galerías de arte que se han ido abriendo en los últimos años, además de los tradicionales teatros y centros culturales de la zona.

En nuestra zona de estudio podemos observar continuas transformaciones en el espacio urbano en la lógica cuádruple de Allen Scott (2007, p. 204): desarrollo económico-cultural, transformación social, cambios funcionales acompañantes y, finalmente, rediseño del entorno urbano. Sin embargo, es preciso no perder de vista que se trata de un entorno que sigue siendo heterogéneo, pues encontramos una zona gentrificada y transformada que convive al mismo tiempo con un barrio aún tradicional donde todavía hay residentes yucatecos que incluso habitan casas deterioradas. Los nuevos y viejos habitantes de Santiago comparten muros, aceras, calles, aunque no estilos de vida. Mireya, nuestra entrevistada yucateca, echa de menos las tardes en la que los vecinos se sentaban en las aceras a tomar el fresco mientras conversaban comiendo charritos y tomando su refresco embotellado. Hoy en día, comenta, sólo seis de sus vecinos son yucatecos; el resto viene del extranjero. A éstos últimos los conoce, sí, incluso sabe sus nombres, pero cuenta que la vida vecinal está lejos de ser lo que era antes. De hecho, su vecina extranjera ha ido a visitarla en la puerta de su tienda, pero solo "conversa dos minutos y se va". Mireya piensa que, entre otras cosas, la barrera del idioma hace difícil la convivencia, aunque la amabilidad es el cotidiano. ${ }^{23}$ Por su parte, Colomé nos comenta que ve a sus vecinos extranjeros "sobre todo de mañana o a las siete de la noche, ya que salen a cenar a los diferentes restaurantes que hay alrededor; están caminando con sus perros". ${ }^{4}$

La proximidad física no es garantía de una proximidad social, pues el espacio no es el único obstáculo de la comunicación y la distancia social no siempre se puede medir en términos puramente físicos (Grafmeyer, 1994). En general, los nuevos residentes, en comparación con los residentes yucatecos, cuentan con mayor solvencia económica, pero, sobre todo, con un mayor capital cultural, pues son más cosmopolitas. Su gusto por la slow food, por los alimentos orgánicos y demás productos delikatessen, los hace consumidores dispuestos a pagar más por ciertos productos que suponen de mayor calidad. El idioma constituye otra barrera cultural y de socialización que se une a los estilos de vida muy diferenciados. Muchos de los extranjeros en el centro histórico hablan un nivel de español bastante elemental. Habría que señalar, sin embargo, que en algunos casos no es por falta de ganas, pues se han vuel-

${ }^{23}$ Entrevista con Mireya en el barrio de Santiago, 17 de octubre de 2018.

${ }^{24}$ Entrevista con Colomé en el barrio de Santiago, 19 de octubre de 2019. 
to muy socorridos los cursos de español a extranjeros que dan instituciones como la UNAM, o incluso los mismos vecinos del barrio, que ven en ello un área de oportunidad. Greenwood nos habló, por ejemplo, de lo difícil que se le ha hecho aprender el idioma, a pesar de los cursos que ha tomado. ${ }^{25}$

En cuanto a la vida social, es evidente que entre los nuevos residentes ésta se desarrolla de puertas para adentro. Greenwood nos cuenta:

Solíamos ir con unos amigos que hacen un wine tasting en su casa. Un día por mes. Y entonces ése era mi círculo [...] y luego solíamos juntarnos para desayunar un día por mes. Ellos eran todos jubilados y conocíamos restaurantes.

El punto de reunión y de integración de este sector social es la Mérida English Library. Greenwood asegura que "todos los expats van ahí los primeros dos años para introducirse porque todos son nuevos en Mérida. Es donde haces muchos amigos". ${ }^{26}$ En un principio, cuenta nuestro entrevistado, era el único lugar donde los expatriados podían reunirse, ofreciendo diversos servicios como libros en inglés, conectar a los recién llegados y organizar diferentes eventos. Entre éstos destaca el House and Garden Tour, en el que una vez por semana, durante el otoño y el invierno, se venden los boletos para escuchar en inglés algunos datos históricos de la ciudad y visitar al menos tres casas habitadas o en renta propiedad de residentes extranjeros. Se trata de una introducción al mercado de bienes inmuebles de la zona, así como un panegírico dedicado a lo que, suponen, es la dulzura de la vida en una casa meridana.

El último aspecto que nos gustaría tocar aquí se relaciona con la dinámica cultural que la gentrificación ha traído a nuestra zona de estudio. Sorprende la proliferación de galerías de arte, pues en un espacio de tres calles observamos la apertura más o menos reciente de siete galerías (véase el Mapa 4). Mérida, por el número de museos, de actividades artísticas y demás, tiene cierta vocación cultural; de hecho, en 2000 y en 2017 fue nombrada Capital Americana de la Cultura. Sin embargo, es preciso reconocer que, hasta cierto punto, la gentrificación ha venido a dinamizar el consumo de bienes culturales en el centro histórico. Según un sondeo realizado en la UADY (Enseñat y Moreno, 2017), las tres principales actividades culturales de los residentes extranjeros encuestados en el centro histórico de Mérida son: ir al cine, 29\%; a los conciertos de música, 18\%; a la orquesta sinfónica

${ }^{25}$ Entrevista con Greenwood en el barrio de Santiago, 23 de junio de 2017.

${ }^{26}$ Entrevista con Greenwood en el barrio de Santiago, 23 de junio de 2017. 
y a la ópera, $13 \%$; y a los museos, también $13 \% .{ }^{27}$ La presencia de los extranjeros en algunos de estos lugares resulta bastante notoria, según lo que nos cuenta Colomé:

Yo acostumbro a ir a los conciertos de la Orquesta Sinfónica los domingos y la realidad es que cuando vas los domingos casi la mitad del teatro es puro extranjero; $\mathrm{y}$ cuando es la temporada, enero-junio, prácticamente siento que estoy en un teatro de Miami: puro inglés, francés y escuchas todos los idiomas, y yo creo que habremos de yucatecos 250 gentes. $^{28}$

\section{Mapa 4}

Galerías de arte en la zona de estudio

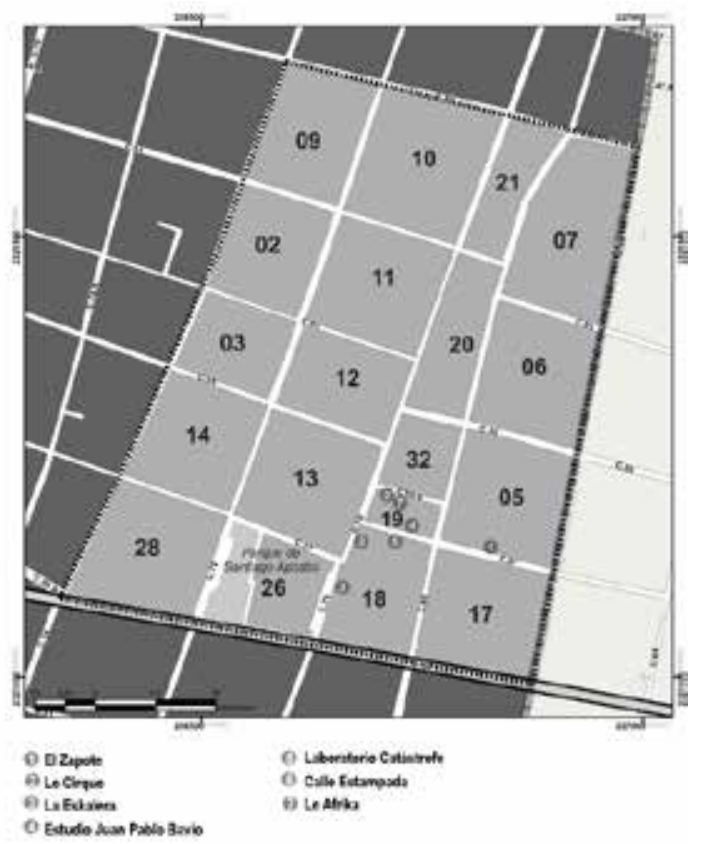

Fuente: Elaboración propia a partir de datos del trabajo de campo realizado de septiembre a noviembre de 2018.

${ }^{27}$ Se encuestó un total de 208 personas residentes, de las cuales 45 eran extranjeros. Ciertamente este sondeo no da suficiencia estadística, pero sí nos da una idea de los gustos culturales de los extranjeros que ahí residen.

${ }^{28}$ Entrevista con Colomé en el barrio de Santiago, 19 octubre de 2018. 


\section{Consideraciones finales}

Hasta aquí hemos analizado algunas de las transformaciones socioterritoriales que han tenido lugar en el centro histórico de Mérida y más específicamente en 19 manzanas que se localizan en el barrio de Santiago. Destacamos que la migración de la población yucateca del centro histórico de Mérida hacia otras zonas no tuvo como origen la llegada de los migrantes extranjeros que vienen sobre todo de Norteamérica. En Mérida, primero se abandonó el centro y después se repobló con algunos extranjeros que vieron que la vida apacible, el valor del mercado inmobiliario y la estética del lugar generaban un cuadro de vida bastante aceptable. Aquí no se trata propiamente de un desplazamiento de población que se empobrece por otra con mayores recursos financieros, sino, como se explicó, fue parte de un proceso de urbanización en el que las políticas públicas a nivel municipal y estatal empujaron, primero, a la descentralización residencial y de los servicios modernos de la ciudad en dirección al norte $\mathrm{y}$, después, abonaron a la turistificación de la zona, volviéndola atractiva a los visitantes y a los nuevos residentes, sobre todo para los adultos mayores del extranjero.

El proceso de gentrificación en el barrio de Santiago es todavía bastante modesto; sin embargo, sí podemos afirmar que de manera paulatina se ha venido imponiendo un nuevo perfil en el que, al menos en nuestra zona de estudio, predomina un entorno con casas completamente renovadas habitadas por residentes extranjeros, al lado de casas que han sido poco intervenidas donde aún viven los yucatecos, o incluso al lado de casas abandonadas y en mal estado. Sólo una parte del barrio de Santiago y del centro histórico de Mérida se ha embellecido y todavía falta mucho para que este proceso se convierta en algo generalizado. El centro histórico de Mérida está muy lejos de lo que sucede en otras ciudades del país, como en San Miguel de Allende, en Guanajuato, por ejemplo.

Lo que sí hemos podido observar es que la llegada de esta migración a Mérida ha generado diferentes efectos en lo económico, social y cultural. La capital yucateca ha pasado de ser una ciudad con un perfil sociocultural muy insular y local a una ciudad mucho más cosmopolita. Los extranjeros son pocos, pero muy visibles. Su estilo de vida los distingue claramente y más en lo que toca a su cultura material. Tal es la razón por la que encontramos en el barrio de Santiago diferenciación, poca integración y cierto contraste entre los nuevos residentes y los antiguos residentes yucatecos.

Un aspecto importante que amerita mayor profundidad tiene que ver con el futuro de este espacio social, cultural, urbano, donde un porcentaje alto de los que ahí habitan, tanto yucatecos como extranjeros, son residen- 
tes de la tercera edad. Este es el nuevo perfil de la población, tanto de la nativa de México como de la de Estados Unidos. El cambio demográfico seguirá generando importantes transformaciones sociales y culturales $\mathrm{y}$, por lo tanto -suponemos- a nivel de política de estado. Al respecto, no es ocioso preguntarse, al paso de los años, ¿quiénes serán los nuevos residentes de estas casas? ¿Llegará un momento en que la pirámide de edades se invierta? La cuestión patrimonial no es anodina, y menos en el centro histórico de Mérida, donde el deterioro de muchas casas se debe a problemas de intestado. ¿Qué pasará con los extranjeros que, debido al marco jurídico de este país, además compran a través de un fideicomiso?

\section{Bibliografía}

Ballina Viramontes, A. P. (2007a). Tradición, transición y modernidad: arquitectura posrevolucionaria en el centro histórico de Mérida. En M. T. Peraza Guzmán (coord.), La memoria inmediata. Patrimonio siglo XX (pp. 82-91). Mérida, Yuc.: Universidad Autónoma de Yucatán, Facultad de Arquitectura.

Ballina Viramontes, A. P. (2007b). ¿Arquitectura menor? En M. T. Peraza Guzmán (coord.), Posrevolución y modernización. Patrimonio siglo $X X$ (pp. 98-109). Mérida, Yuc.: Universidad Autónoma de Yucatán, Facultad de Arquitectura.

Bantman-Masum, E. (2015). You need to come here... to see what living is really about. Staging North American expatriation in Merida (Mexico). Miranda, 5. Recuperado de https://journals.openedition.org/ miranda/2494\#text

Benson, M. y O'Relly, K. (2009). Migration and the search for a better way of life: A critical exploration of lifestyle migration. The Sociological Review, 57(4): 608-625. Recuperado de https://doi.org/10.1111/j.1467954X.2009.01864.X

Bourdieu, P. (1979). La distinction. Critique sociale du jugement, París, Francia: Les Éditions de Minuit.

Bourdieu, P. (2000). Les structures sociales de l'économie. París, Francia: Seuil.

Cuarto Informe de Gobierno (2016). Yucatán. Recuperado de http://www. yucatan.gob.mx/docs/transparencia/informes/2001_2007/4to/TEXTO_ INFORME_IV.pdf

Diario Oficial de la Federación (1982). Decreto por el que se declara una zona de monumentos históricos en la Ciudad de Mérida, Yucatán. Recu- 
perado de http://www.museodelaluz.unam.mx/assets/yucatan/decretozonas-monumento-merida.pdf

Enseñat, F. y Moreno, E. (coords.). (2017). Consumo cultural de residentes del centro histórico de Mérida, Yucatán. [Encuesta realizada con la colaboración de estudiantes de la licenciatura en turismo de la UADY]. Mérida, Yuc.: inédito.

Escalante Ceballos, F. (2016). Alegría y nostalgia. Semblanza de mi barrio. Mérida, Yuc.: Edición del autor.

González Canto, E. (2016). El desarrollo en las décadas intermedias. Las bases de la modernización de Mérida en el siglo XX. Revista de la Universidad Autónoma de Yucatán. Urbanismo, 31(269), 24-54. Recuperado de http://www.cirsociales.uady.mx/revUADY/pdf/269/ru269-3.pdf

Gotham, K. (2005). Tourism gentrification: The case of New Orleans' Vieux Carré (French quarter). Urban Studies, 42(7), 1099-1121. Recuperado de https://journals.sagepub.com/doi/pdf/10.1080/00420980500120881

Gotham, K. (2018). Evaluation et approfondissement du concept de gentrification touristique. Via Tourism Review, 13. Recuperado de https:// journals.openedition.org/viatourism/2199\#text

Grafmeyer, Y. (1994). Regards sociologiques sur la ségrégation. En J. Brun y C. Rhein (eds.), La ségrégation dans la ville (pp. 85-117). París, Francia: L'Harmattan.

Hiernaux, D. y González, C. I. (2014). Turismo y gentrificación: pistas teóricas sobre una articulación. Revista de Geografia Norte Grande, 58, 55-70. Recuperado de https://scielo.conicyt.cl/pdf/rgeong/n58/art04. pdf

INEGI. (2016). Marco geoestadístico nacional. Aguascalientes, Ags.: Instituto Nacional de Estadística y Geografía: Recuperado de https://www.

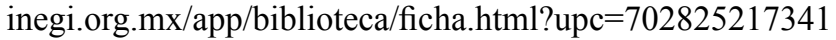

INEGI. (s/f). Espacio y datos de México. Aguascalientes, Ags.: Instituto Nacional de Estadística y Geografía. Recuperado de https://www.inegi. org.mx/app/mapa/espacioydatos/

Iracheta, A. y Bolio, J. (2012). Mérida metropolitana. Propuesta integral de desarrollo. Mérida, Yuc.: Fundación Plan Estratégico de Yucatán A.C.-Comey / Conacyt / Centro Eure.

López Santillán, R. (2011). La metrópoli meridana, principales tendencias socioespaciales. Península, 6(1), 47-81. Recuperado de http://www. scielo.org.mx/scielo.php?script=sci_arttext\&pid=S1870-57662011 00010

Peraza Guzmán, M. T. (2012). La aportación patrimonial de la vivienda del siglo XX en el centro histórico de Mérida, Yucatán. Bitácora Arqui- 
tectura, 24, 43-49. Recuperado de http://www.revistas.unam.mx/index. $\mathrm{php} / \mathrm{bitacora} /$ article/view/62183/54747

Pérez Campuzano, E. y Gamallo, P. (2014). Tendencias recientes de la migración desde y hacia Mérida. En R. López Santillán y L. A. Ramírez (eds.), Crecimiento urbano y cambio social: escenarios de transformación de la zona metropolitana de Mérida (pp. 85-104). Mérida, Yuc.: Universidad Nacional Autónoma de México, Centro Peninsular en Humanidades y Ciencias Sociales.

Pérez Medina, S. y Torres Pérez, M. E. (2016). Nuevos usos y usuarios en la vivienda del centro histórico de Mérida, Yucatán. En A. Balandro, V. Valero y A. Ziccardi (coords.), Conservación y desarrollo sustentable de centros históricos (pp. 179-207). México: UNAM / Conacyt / INAH / Secretaría de Cultura.

Pérez Pérez, M. J. (1991). Rescate integral del barrio de Santiago: vivienda multifamiliar. (Tesis de licenciatura, Universidad Autónoma de Yucatán, Facultad de Arquitectura, Mérida). Recuperado de http://opac. uady.mx/opac/sisbiuadyOPAC.php\#

Plan Estatal de Desarrollo 2012-2018. Yucatán. Mérida, Yuc. Recuperado de http://www.yucatan.gob.mx/docs/transparencia/ped/2012_2018/ PED_2012_2018.pdf

Programa Especial de Fomento Turístico 2013-2018. Yucatán. Mérida, Yuc. Recuperado de http://siegy.yucatan.gob.mx/archivos/Programa_ Especial_Fomento_Turistico.pdf

Ramírez, L. A. (1993). Sociedad y población urbana en Yucatán 19501989. Ciudad de México: El Colegio de México, A.C. (Cuadernos del Centro de Estudios Sociológicos).

Ramírez, L. A. (2006). Mérida, una modernidad inacabada. Un siglo de población y empleo urbano. Mérida, Yuc.: Fundación Plan Estratégico de Mérida.

Reyes Pérez, R. (2012). Habitabilidad y espacio público en barrios históricos de Mérida, Yucatán, al inicio del siglo XXI. (Tesis de doctorado en Arquitectura, UNAM, Facultad de Arquitectura, México).

Sabatini, F., Robles, M. y Vásquez, H. (2009). Gentrificación sin expulsión, o la ciudad latinoamericana en una encrucijada histórica. Revista 180, 24, 18-25. Recuperado de http://www.revista180.udp.cl/index.php/ revista180/article/view/266

Scott, A. (2007). ¿Capitalismo y urbanización en una nueva clave? La dimensión cognitivo-cultural. Tabula Rosa. Revista de Humanidades, 6, 195217. Recuperado de http://www.redalyc.org/articulo.oa?id=39600609 


\section{Acerca de los autores}

Claudia Dávila Valdés es licenciada en Relaciones Internacionales por la Universidad Nuevo Mundo; maestra en Estudios de las Sociedades Latinoamericanas por el Instituto de Altos Estudios sobre América Latina, Université de la Sorbonne Nouvelle, Paris III; y obtuvo el doctorado en Sociedades Occidentales, Tiempo, Espacio y Civilización, en la Université Paris VII, Denis Diderot. Participó como posdoctorante en el Centro Peninsular en Humanidades y Ciencias Sociales, de la Universidad Nacional Autónoma de México. Ha sido profesora a nivel licenciatura y maestría en diversas instituciones. Actualmente es profesora-investigadora del Centro de Investigaciones Regionales, Unidad de Ciencias Sociales, de la Universidad Autónoma de Yucatán, incorporada a través del programa de Repatriaciones y Retenciones del Conacyt. Sus investigaciones versan sobre temas migratorios y el impacto de estos movimientos poblacionales en las sociedades de acogida; se enfoca en aspectos de movilidad social y geográfica, así como en procesos de integración. ORCID: https://orcid.org/0000-0002-7636-2695

Entre sus publicaciones se encuentran:

Dávila, C. (2018). Libaneses y coreanos en Yucatán. Historia comparada de dos migraciones. Mérida, Yuc.: Universidad Nacional Autónoma de México, Centro Peninsular en Humanidades y Ciencias Sociales.

Dávila, C. (2015). Socio-economic trajectory and geographical mobility of Lebanese and Koreans. From Motul to Mérida. Migraciones Internacionales, 8(2), 103-131. Recuperado de http://www.scielo.org.mx/ scielo.php?script $=$ sci_abstract\&pid $=$ S1665-89062015000200004\& lng $=$ es\&nrm $=$ iso

Dávila, C. (2012). Refugiados españoles en Francia y en México. Un estudio comparativo (1939-1951). Ciudad de México: El Colegio de México, A.C. (Ambas Orillas).

Ricardo López Santillán es licenciado en Sociología por la Universidad Nacional Autónoma de México (UNAM), donde obtuvo la medalla Gabino Barreda al mejor promedio de su generación. Es maestro y doctor en Sociología por la Université de la Sorbonne Nouvelle, Paris III. Es investigador en el Centro Peninsular en Humanidades y Ciencias Sociales de la UNAM, en Mérida, Yucatán; en dicha institución también es titular de la Secretaría Académica. Es miembro del Sistema Nacional de Investigadores, nivel I. Es responsable de la investigación colectiva "La metropolización de Mérida y su impacto sociocultural en cuatro localidades periurbanas", con apoyo de Fondos Mixtos Conacyt y Gobierno de Yucatán; asimismo, es responsable 
técnico de la Red-Conacyt "Centros Históricos de ciudades mexicanas". Ha impartido cursos de licenciatura, maestría y doctorado en distintas instituciones. Sus líneas de investigación son: espacio urbano, estructura de clases sociales, cambio sociocultural y etnicidad en la ciudad. ORCID: https:// orcid.org/0000-0003-0888-4819

Entre sus publicaciones se encuentran:

López Santillán, R. (2011). Etnicidad y clase media. Los profesionistas mayas residentes en Mérida. Mérida, Yuc.: Universidad Nacional Autónoma de México, Centro Peninsular en Humanidades y Ciencias Sociales / Consejo Nacional para la Cultura y las Artes.

López Santillán, R. (2008). Clase media capitalina: recomposición de su espacio social y urbano (1970-2000), Mérida, Yuc.: Universidad Nacional Autónoma de México, Centro Peninsular en Humanidades y Ciencias Sociales.

López Santillán, R. y Ramírez, L A. (eds.). (2014). Crecimiento urbano y cambio social: escenarios de transformación en la Zona Metropolitana de Mérida. Mérida, Yuc.: Universidad Nacional Autónoma de México, Centro Peninsular en Humanidades y Ciencias Sociales.

Samuel Jouault es titulado en Ingeniería de Proyectos de Desarrollo por la Université de Bordeaux, licenciado y maestro en Geografía por la Université de Rennes, y doctor en Geografía por la Université Angers, todo en Francia. Fue profesor invitado en la Universidad Nacional Autónoma de México y en la Université Angers. Actualmente es profesor e investigador asociado a la Facultad de Ciencias Antropológicas de la Universidad Autónoma de Yucatán, e investigador asociado en el Laboratorio Espacios y Sociedades y el Centro de Estudios Mexicanos y Centroamericanos. Forma parte del Comité Académico Nacional de Turismo Rural. Es candidato al Sistema Nacional de Investigadores. Ha desarrollado una línea de investigación sobre las interacciones entre el turismo y las sociedades locales en los espacios rurales de América Latina. ORCID: https://orcid.org/00000003-4419-900X

Entre sus publicaciones se encuentran:

Jouault, S. (2018). Mayas d'hier et d'aujourd'hui. Le rôle des sociétés locales dans le développement touristique. Rennes, Francia: Presses Universitaires de Rennes.

Jouault, S. (dir.) (2015). Ek Balam de la milpa al turismo [video documental]. Temozón, Yuc.: Universidad Autónoma de Yucatán / Actuar Localmente por un Turismo Ecológico y Responsable, A.C. Recuperado 
de https://www.academia.edu/20364007/Ek_Balam_de_la_milpa_al_ turismo

García de Fuentes, A., Jouault, S. y Romero, D. (2015), Atlas de turismo alternativo en la Península de Yucatán, Mérida: UADY / Cinvestav, IPN.

Recepción: 7 de diciembre de 2018. Aceptación: 18 de febrero de 2019. 
